\title{
A MUlher JUnto Às CRiminologias: \\ DE DEGENERADA À VÍTIMA, SEMPRE SOB CONTROLE SOCIOPENAL
}

Simone Martins ${ }^{\star}$

\begin{abstract}
Resumo
Este artigo apresenta figuras referentes à mulher junto às criminologias, bem como discute suas repercussões no código penal brasileiro. É identificada na criminologia positivista a figura da criminosa nata relacionada à prostituição, à mulher masculinizada e à atávica; bem como da vítima, seja ela criminosa por dependência do homem, seja pela necessidade de proteção do Estado. Estas figuras têm em comum o fato de servirem ao controle social da mulher. Em oposição, na criminologia feminista se verifica a figura da mulher emancipada, que não busca no direito penal a solução de conflitos que são de ordem social, econômica e política.

Palavras-chave: criminologia; mulher; estigma; sistema penal.
\end{abstract}

\section{WOMAN IN CRIMINOLOGY: FROM DEGENARATE TO VICTIM,}

\section{ALWAYS UNDER SOCIAL PENAL CONTROL}

\begin{abstract}
This article presents figures reffering to woman in criminology, as discusses its repercussions in the Brazilian penal code. Identified in positive criminology the figure of the nate criminal related to prostitution, masculine woman and atavistic; as well as the victim, is her a criminal dependent of a man, or is it by the necessity of protection from the Government. These figures have in common serve to social control of woman. In opposition, in feminist criminology it is identified the figure of the emancipated woman that does not search in penal law the solution of conflicts related socially, economically and politically.
\end{abstract}

Keywords: criminology; woman; stigma; penal system.

\footnotetext{
^ Psicóloga e Mestre pela Universidade Federal de Santa Catarina. Membro-fundadora do Grupo de Psicologia Jurídica de Santa Catarina. Endereço: Rua Ivo Reis Montenegro, 51, apto 11 - bairro Itaguaçu, 88085-600, Florianópolis - SC.

E-mail:smartins27@yahoo.com.br
} 
Historicamente, na sociedade ocidental, diversas figuras referentes à mulher emergiram. A dona de casa, a operária, a revolucionária, entre outras. No entanto, a proposta do presente artigo é apresentar algumas das figuras femininas situadas especificamente junto aos movimentos criminológicos. Suas definições costumam se restringir a pesquisas no campo jurídico. Em muito, isso se deve ao fato de que a criminologia permanece uma disciplina pouco difundida entre as áreas humana e social, mantendo-se relacionada ao direito ainda que seu corpo seja multidisciplinar. Da mesma forma, referências acerca da mulher nas codificações jurídicas são comumente identificadas em textos, mas sem relacioná-las a estes discursos que refletem as sociedades e o direito de determinados momentos históricos. Assim, não se objetiva aqui a explanação das punições e normatizações do direito ocidental, mas sim, de alguns dos discursos que possibilitaram a emergência destas rotulações de degeneradas e vítimas - papéis frequentemente ocupados pelas mulheres junto ao direito penal - bem como da figura da mulher emancipada que progressivamente ganha espaço nas discussões criminológicas.

\section{Três dos principais discursos Criminológicos do OCIDENTE Moderno}

A criminologia é uma disciplina que, embora comumente vinculada ao direito, contempla e dialoga com diversos saberes, como a biologia, a psicologia, a psicanálise, a antropologia, a sociologia e a estatística. Abordar sua trajetória, seus discursos e seus enunciados seria de extrema complexidade, portanto faz-se necessário um recorte no qual esta disciplina seja introduzida com fins de atender a proposta deste artigo. Recorte este capaz de apresentar os chamados paradigmas criminológicos e dar base para a discussão acerca das figuras femininas neles identificadas.

Ainda que estudos acerca da criminalidade estivessem presentes desde a Antiguidade, é a partir da sistematização de algumas teorias que a criminologia é reconhecida como tal e difundida até os dias atuais. Assim, a história habitualmente contada deste saber destaca três momentos: clássico, positivista e crítico.

Expondo de maneira breve esses momentos, têm-se, no século XVIII, a Escola Clássica emergindo do Iluminismo, do discurso humanitário e de uma série de transformações estatais, sociais e econômicas - incluindo o destaque ao capitalismo. As teorias do direito penal se valeram desse momento no qual a racionalização acerca do sistema punitivo colocou em discussão o conceito de crime - definindo-o em termos legais e apresentando-o como uma violação de direitos decorrente do livre-arbítrio de seu autor (ANDRADE, 1997; ROSA, 2005). A responsabilidade penal e individual foi, dessa forma, relacionada às violações conscientes, e a pena foi estabelecida como retribuição pelo mal causado à sociedade e como forma de prevenção da criminalidade via intimidação dos sujeitos. Não houve, nesse discurso, destaque para análises do sujeito criminoso, embora ele estivesse enunciado a partir da concepção de livre-arbítrio. Considera-se que o enfoque dado por este movimento foi na ilegalidade do ato crime. 
Andrade (1997), Castro (2005) e Rosa (2005) apontam para o segundo momento da criminologia, a partir da segunda metade do século XIX, quando os postulados da ciência positivista e a necessidade do direito penal de olhar para o autor do crime como peça fundamental do sistema punitivo proporcionaram a emergência do discurso criminológico positivista. Como no movimento anterior, uma ideia de crime e responsabilidade penal esteve presente, porém o crime foi apresentado como fato natural e social, bem como o livre-arbítrio deu lugar ao determinismo biológico, social e psíquico, ocorrendo a emergência do chamado paradigma etiológico. Segundo os citados autores, a empiria se impôs como meio para demonstrar as tendências criminosas do sujeito e sua periculosidade nata, e a pena passou a ser considerada tanto uma forma de salvação desse desviado quanto, e principalmente, proteção da sociedade. Esse foi um discurso usado para legitimar a defesa social e a prisão com fim de defesa dos cidadãos "de bem" daqueles que supostamente impediriam o exercício de sua cidadania plena. Uma proteção necessária, segundo esse discurso, pois nem todo o criminoso seria nato, mas o verdadeiro criminoso, sim, apresentando um germe dentro de si que impediria a ressocialização (LOMBROSO, 2001[1876]). Quanto aos outros tipos de criminosos, aqueles cuja ressocialização foi indicada pela criminologia positivista como possível, deveriam participar de tratamentos penitenciários para retornar ao convívio da sociedade cumprindo, a partir daí, os pactos sociais.

Já na segunda metade do século XX, numa oposição ao Positivismo, deuse a ascensão da chamada criminologia crítica e da teoria da reação social ao status de paradigma. Como indicam Andrade (1997), Castro (2005) e Rosa (2005), a criminologia crítica participou de um processo de transformação social e teórico, fazendo uso principalmente da influência do materialismo-histórico, da teoria do labelling aproach (etiquetamento), do interacionismo e da etnometodologia. $\mathrm{O}$ discurso criminológico crítico não apresentou uma homogeneidade de teorias, sendo adaptado de acordo com cada país por criminólogos. No entanto, em comum às teorias deste movimento, apresentou-se a mudança de foco do autor de crimes para o contexto social no qual ele se insere, propenso às relações de poder de ordem macro e microssocial, à estigmatização e ao etiquetamento, à reação social e à criminalização anterior ou posterior ao delito. $\mathrm{O}$ olhar para o sujeito como causa e consequência da criminalidade deu espaço para análises sociológicas do sistema penal formal e informal - comprometendo a sociedade como um todo no processo da criminalidade na medida em que o controle social não se limita às instituições jurídicas. Os citados autores apontam a crítica desse paradigma ao direito penal, que assumiu historicamente a forma de controle sócio-penal repressor e legitimador da exclusão - e não mecanismo de defesa ou de justiça social como se declarou oficialmente.

No entanto, o discurso criminológico crítico não substituiu o positivista no decorrer da história, ocorrendo no final do século XX uma diversificação de enunciados neste cenário. Passaram a dividir a cena dois discursos criminológicos que são fechados; que representam aspectos bastante característicos, momentos de rupturas históricas, de diferentes influências e convergências. Seus principais objetos de estudos - o crime na criminologia clássica, o criminoso na criminologia 
positivista, o sistema penal na criminologia crítica -, suas concepções de sujeito e suas propostas apresentam divergências. Ainda assim, apesar de suas diferenças, eles convivem no século XXI na sociedade ocidental, em sua Academia e em sua Justiça. A Justiça brasileira, inclusive, sofre o reflexo dessas criminologias e dos estereótipos por elas fabricados - principalmente das duas primeiras, considerando que a criminologia crítica ocupa-se em desconstruí-los. Estigmas que se adaptam às culturas, variando conforme a localidade, mas que apresentam uma permanência por serem decorrentes também de outros saberes, sendo assumidos pelo senso comum e refletidos até mesmo na literatura ficcional, explorados pela mídia, numa ampla e complexa rede mantenedora e solidificadora de estigmas e sistemas repressores. E a partir desta compreensão, e com base nos principais discursos criminológicos do Ocidente Moderno, é possível realizar uma análise acerca das figuras femininas neles identificadas.

\section{AS FIGURAS FEMININAS IDENTIFICADAS NOS DISCURSOS CRIMINOLÓGICOS}

Embora a proposta deste artigo apresente-se junto à criminologia - sendo esta aqui considerada a partir da sistematização já citada - um breve resgate ao momento anterior a esta se faz necessário para citar a figura feminina relacionada à transgressão das regras sociais. Num período em que a Inquisição foi importante sistema punitivo, a mulher sentenciada como bruxa assim o foi por representar um risco à ordem moral e política estabelecida pela Igreja - a transgressão disfarçada de pecado mortal para fins de controle. Uma ordem fincada no ideal de família, de uma moral cristã, que unida a tantos fatores sociais vigentes na época colaboraram para a dicotomia, herdada até os dias atuais entre homem e mulher, o que é ou não feminino. Esta ordem foi estabelecida desde momentos anteriores em algumas sociedades, porém recebeu uma roupagem moralista que influenciou diretamente a figura da mulher nos discursos criminológicos que o seguiram. Embora a ciência tenha rompido com a Igreja, a moral cristã relacionada à sexualidade permaneceu nas entrelinhas, facilmente percebida nos discursos criminológicos. Discursos, estes que fizeram uso também do discurso médico e psicanalítico acerca da sexualidade e das diferenças entre masculino e feminino, sendo transmitido entre gerações e participando da formação cultural assimétrica que impõe estereótipos relacionados a papéis sexuais (SILVA, 1983).

\section{A figura da MUlher do SÉculo XVIII e Primeira metade do SÉculo XIX}

Com o advento do capitalismo, a burguesia necessitava proteger seus bens tanto quanto a economia necessitava de mão de obra especializada e barata. Emergiu, então, um grupo de juristas e filósofos chamados de reformadores que, com um discurso humanitário contra a destruição do corpo (típica dos suplícios de períodos anteriores), propuseram tanto a modificação do sistema punitivo quanto a tipificação legal de determinados crimes (FOUCAULT, 2004). Grande parte das codificações ocidentais teve sua inspiração neste momento no qual o patrimônio e a moral buscaram ser preservados por meio de leis penais. Se o discurso criminológico clássico, aqui emergente, teve o foco na ilegalidade do ato crime, classificando-o e determinando punições específicas para cada tipo, a mulher criminosa 
teve tanto destaque quanto o homem, sendo observadas diferenciações apenas relacionadas à tipicidade do crime em si, por exemplo, à prostituição atribuída à mulher. Isso porque, como citado anteriormente, o sujeito autor de crimes foi enunciado por este discurso como um ser munido de livre-arbítrio, sem maiores pesquisas acerca de fatores criminógenos propulsores ao delito. Um ser social que poderia ser inclusive levado pelas más leis a ofender outrem sem benefício para si próprio (BECCARIA, 1998[1764]). Um sujeito igual a tantos outros que mantêm os pactos sociais e não transgridem as leis.

$\mathrm{Na}$ Europa, neste momento, os códigos apresentavam crimes referentes à vagabundagem, à homossexualidade e à prostituição. E é a figura da prostituta como degenerada moral e criminosa que pode ser considerada, nesta análise, a primeira figura feminina de destaque nos discursos criminológicos. Se o discurso clássico ocupou-se apenas em definir a prostituição como ato crime passível de punição, o discurso policial da primeira metade do século XIX arriscou-se a explorar um pouco mais o tema. É importante ressaltar que este discurso não é sistematizado por juristas como parte integrante da criminologia pois não apresenta a cientificidade exigida em seu tempo para alcançar o status de paradigma (ZAFFARONI, 2005). De fato, o discurso criminológico policial é pouco difundido na Academia sem, no entanto, perder sua importância principalmente no tocante à figura da prostituta como transgressora da lei.

Este foi um discurso baseado exclusivamente em aspectos morais que enunciava o vício como causa de todos os males e que, embora sendo inerente à natureza humana, as classes menos privilegiadas seriam as mais viciosas e as mais perigosas, considerando que as classes dominantes dissipariam seus vícios de maneiras variadas (ZAFFARONI, 2005). Estes vícios, segundo o autor, eram caracterizados como a preguiça, o jogo, a libertinagem e as paixões consideradas baixas e imorais.

Especificamente sobre a mulher, em 1840, o chefe de polícia Frégier afirmou que as mulheres, ainda que em menor número, ocupariam um rol importante como causa de todos os tipos de atentados que afligem a sociedade (ZAFFARONI, 2005). Dentre as consideradas depravações exercidas pelas mulheres estariam: a prostituição, a sedução, a cumplicidade no estelionato e os roubos. Dessa forma, a importância da família como instituição repressora foi salientada pela indicação de que os pais deveriam cuidar das filhas que trabalhavam em oficinas e no comércio, pois estes seriam locais onde nem sempre imperaria a decência e, principalmente no caso das operárias, a desestrutura familiar e as desilusões amorosas e matrimoniais impulsionariam a mulher à prostituição (ZAFFARONI, 2005). Segundo o citado autor, o discurso policial também apontava para as operárias como candidatas à gravidez precoce e abandono por parte dos operários que a engravidavam, sendo indicada pelas estatísticas policiais da época, também, uma tendência dessas mulheres à embriaguez. Assim, ainda que a criminalidade feminina da época não fosse restrita à prostituição, foi relacionada diretamente a uma sexualidade considerada imoral até então. 
Ainda no que diz respeito à prostituição - na época regulamentada em algumas cidades européias, embora não aceita moralmente, visto que os fins da regulamentação eram de mapeamento e controle - o discurso policial preocupava-se com as clandestinas, aquelas que se negavam à inscrição no mapeamento da polícia parisiense afetando "severamente a moral" (ZAFFARONI, 2005). A importância do registro policial voluntário por parte das prostitutas, segundo o chefe de polícia francês, residia no fato de estas tenderem a não cometer crimes e na intervenção da instituição para devolver a mulher a sua família. A considerável porcentagem de mulheres de uma mesma família atuando como prostitutas foi suficiente para justificar a idéia de corrupção moral entre as famílias das classes menos afortunadas. Apresentava-se neste discurso, também, uma análise de acordo com as classes de prostitutas, em que a menor parcela correspondia às prostitutas livres, luxuosas, que cobravam caro e tinham amantes poderosos; seguidas pelas de classe média que atendiam estudantes de direito e jovens advogados; finalizando com as prostitutas pobres, consideradas as mais corruptas e propensas a delitos para além da prostituição, como o roubo (ZAFFARONI, 2005).

Para todas as classes de criminosos havia propostas para a prevenção da criminalidade, sendo possível identificar algumas relacionadas ao controle dos delitos femininos como: melhorias das condições de trabalho nas fábricas; recuperação dos valores cristãos; educação; melhoramento das moradias; incentivo ao casamento; supressão dos impostos; atividades recreativas nos domingos e festas, a fim de evitar o consumo de álcool; maior repressão dos jogos, por serem considerados a porta de entrada de muitos vícios; introdução de hábitos de ordem entre as prostitutas, por meio de damas de caridade e comissários de polícia (ZAFFARONI, 2005). Para o citado autor, o discurso policial acerca da criminalidade esteve carregado de preconceitos, senso comum e de um moralismo simplista. Ainda que sem contar com o suporte da ciência - como contou o discurso criminológico positivista na segunda metade do mesmo século - estas pesquisas e estatísticas policiais romperam com a ideia clássica de que todos seriam igualmente munidos de livre-arbítrio pois, segundo elas, as classes pobres seriam aquelas as quais temer, repletas de vícios e degenerações morais que afrontavam a sociedade civilizada. A mulher grávida e solteira, dada aos jogos, ao álcool, à libertinagem, dada aos vícios, seria, então, uma candidata à criminalidade.

\section{A figura da MUlher da SEgunda metade do SÉCulo XIX e Primeira METADE DO SÉCULO XX}

Se no século XVIII havia uma demanda da burguesia pela tipificação dos crimes a fim de proteger seus interesses, no século XIX, a proposta foi aumentar o controle social designando grupos aos quais temer e dos quais se proteger. E neste clamor, o discurso criminológico positivista não se diferiu tanto quanto aos crimes e sujeitos candidatos à criminalidade apontados pelo discurso policial, mas sim pela legitimidade via cientificidade, justificando a existência de sujeitos perigosos não pela moral, mas por tendências biopsicossociais que germinavam nas classes menos afortunadas. Assim, a mulher com tendências ao delito não mais foi apontada por seu gosto por vícios, mas pela existência de um germe 
criminoso em si, variante conforme os fatores criminógenos envolvidos que a impelia, também, aos vícios. De degenerada moral à degenerada num sentido mais amplo, a figura da mulher na criminologia permaneceu a de uma anormal pertencente às classes subalternas.

Emergiram, então, as figuras do homem médio e da mulher honesta. O primeiro seria aquele que acata os pactos sociais e não comete delitos. Em sua versão feminina, a chamada mulher honesta teria seu estereótipo pautado na maternidade e na fidelidade, recato e virgindade, com uma sexualidade condizente com a sua idade e estado civil. Corresponde dizer que a mulher honesta representa o pólo oposto da prostituta (SILVA, 1983). E, quando emergiu o discurso criminológico positivista, de cunho biologicista, surgiram estudos anatômicos e fisiológicos que compararam a mulher criminosa considerada anormal e a mulher honesta. No entanto, em relação ao estudo com os homens criminosos - que apresentavam anomalias específicas e em grande quantidade, facilmente diferençável do homem médio - as mulheres criminosas não apresentaram diferenças significativas. Isso porque as criminosas teriam um número mínimo de anomalias, tanto quanto as mulheres honestas (LOMBROSO, 2001[1876]). Não significa afirmar que as pesquisas positivistas não concluíram uma anormalidade na mulher criminosa, mas que, em termos gerais, ela não seria tão significativa quanto a encontrada entre os homens. Deve-se considerar, ainda, que neste discurso a mulher moralmente irrepreensível também era considerada inferior ao homem, possuidora de uma passividade e dependência em relação a ele. Uma das razões dessa passividade foi relacionada à imobilidade do óvulo em contraposição com a atividade do espermatozóide e, por consequência, do homem, apontando uma maior tendência criminosa do homem que da mulher (SOARES, 1986). Desta forma, a mulher criminosa foi considerada um monstro a partir de sua dupla exceção: cometer um crime e ter uma tendência criminosa menor do que o homem (VENERA, 2003).

Resultados considerados significativos foram identificados por estes cientistas quando comparados estudos de mulheres criminosas aos de homens médios, sendo identificada uma aproximação biológica entre eles visto que estas mulheres apresentavam certa virilidade (LOMBROSO, 2001[1876]). Esta virilidade foi relacionada com mulheres criminosas no geral, não sendo específica em casos de condenação por lesbianismo. Assim, para além da figura da prostituta, emergiu neste momento a figura da criminosa masculinizada, visto que a frágil donzela não ofereceria perigo à sociedade. Na ruptura do estereótipo de feminilidade, a criminalidade feminina foi somada ao uso da agressão, colocando a mulher criminosa como semelhante ao homem em casos em que a lesão corporal seria decorrência ou objetivo do comportamento delituoso (VENERA, 2003). Segundo a citada autora, os estereótipos femininos relacionados à violência não são autorizados socialmente como os masculinos o são; em contrapartida, criou-se um estereótipo feminino de fragilidade física e impossibilidade de uso da agressão.

É importante ressaltar que, na transposição do tempo, estas figuras femininas da criminalidade apresentadas por estes discursos criminológicos, até agora citados, persistiram. Grande parte dos códigos ocidentais modernos, incluindo 
os brasileiros, utiliza-se de enunciados clássicos e positivistas em seus artigos. $\mathrm{O}$ código penal brasileiro de 1940 ainda apresenta o ideal de mulher honesta e a criminalidade decorrente de ações contrárias as delas esperadas. Da mesma forma, a figura da criminosa masculinizada permanece viva no imaginário popular e de alguns magistrados. Uma figura calcada pelo discurso criminológico positivista como detentor de uma periculosidade nata, uma anormalidade sem possibilidade de tratamento, tanto quanto a figura da prostituta.

Para este discurso, a figura da prostituta seria a de uma mulher dada a vícios, a paixões, à preguiça, com um alto grau de reincidência, pois não usufruiria da prisão para se reeducar, preferindo continuar com uma vida de imoralidade, não se limitando apenas à prostituição e à troca constante de amantes, mas cometendo diversos delitos (LOMBROSO, 2001[1876]). A prostituição encontrase historicamente relacionada a uma ideia de desonestidade e ameaça à família (VENERA, 2003) e por isso a afirmativa de que a prostituta seria o equivalente ao homem criminoso por residir em seus comportamentos uma periculosidade maior do que nos outros crimes considerados tipicamente femininos, como o aborto e o infanticídio (ZAFFARONI, 2005).

Quanto a estes crimes considerados femininos, o discurso criminológico positivista justificou-os pelo enunciado do atavismo. Este corresponderia a uma das principais características do criminoso nato, ou seja, sua semelhança com os povos considerados primitivos. E é por este enunciado que são justificados e identificados alguns crimes que teriam sua origem na hereditariedade de determinados comportamentos, como o aborto premeditado, comum entre os ditos selvagens por diversos motivos como regras morais, religiosas e preservação econômica, e ainda identificado em algumas mulheres da Modernidade (LOMBROSO, 2001[1876]). Embora, segundo este discurso, a maternidade amenizaria uma condição perversa apresentada pela mulher, a criminosa nata e atávica, não teria pelo filho um afeto maternal.

Além das figuras estereotipadas das criminosas natas identificadas como masculinizadas, prostitutas e/ou atávicas, emergiu também a figura da mulher vítima. Intimamente relacionada com a figura da mulher honesta e dependente do homem, a mulher criminosa caracterizada como vítima permanece até os códigos atuais quando não identificada como criminosa nata e de alta periculosidade ressaltando que esta categoria de criminosa perigosa ainda permanece em menor número em comparação ao homem. A figura da mulher que, embora cometa crimes, é vítima, apresenta-se tanto nas alegações dos advogados de defesa quanto nos próprios códigos que apresentam atenuantes fisiológicos e psicológicos para seus delitos. Desta forma, Pieper (1992) e Venera (2003) afirmam, a partir de suas pesquisas, que na maioria dos casos, independente do crime de infanticídio, de lesão corporal ou homicídio por legítima defesa, furtos, tráfico de entorpecentes, receptação ou estelionato, as mulheres seriam investidas de vitimização e ingenuidade típicas do estereótipo feminino no qual desempenham, frequentemente, o papel de cúmplice do homem. 
Para além da figura da criminosa-vítima, o código penal brasileiro apresenta uma figura feminina vítima de crimes e que precisa de proteção. Principalmente no que diz respeito aos crimes cometidos contra a sua sexualidade, como o abuso sexual, a sedução e o rapto, porém sempre enaltecendo a mulher honesta como vítima, representando um código protetor da sexualidade feminina e repressor daquele que não o respeita, no caso, o homem (CAMPOS, 1998; SILVA, 1983). Esta proteção não tem a ver com um cuidado a vítimas de violência constante mas, como afirmam as citadas autoras, a uma sexualidade feminina normatizada, institucionalizada antes mesmo das leis pelo modelo familiar burguês que coloca o direito como protetor apenas daquela figura esperada e determinada pela sociedade, sendo considerado o crime sempre em função da postura da mulher atacada. A própria categorização dos crimes contra a sexualidade feminina é a de crimes contra os costumes, ou seja, contra a moral pública sexual. Esta moral diz respeito aos hábitos da vida sexual aprovados e disciplinados pela sociedade, cabendo à mulher uma relação entre a passividade feminina e a atividade masculina, restando a ela a liberdade de não aceitar o ato e ao homem de não fazê-lo, impondo à mulher uma liberdade dependente do homem (SILVA, 1983). A figura da mulher vítima, identificada tanto na criminologia quanto no direito penal, nada tem a ver com a preocupação do Estado para com os seus direitos, mas com o controle deste corpo e desta subjetividade. Protegendo, desta forma, a sociedade ao impor a postura de mulher honesta, protegendo direitos sucessórios da família ao limitar sua sexualidade, preservando a moral e costumes para além da segurança da mulher.

\section{A figura da mulher a Partir da Segunda metade do SÉculo XX}

E enquanto os discursos criminológicos clássico e positivista marcam presença nas leis penais, a criminologia crítica apresenta-se com o intuito de desconstruir os preceitos que as mantém. Desta forma, compreendendo que a criminalização dos comportamentos considerados antisociais atingem apenas uma parcela da população rotulada, estigmatizada e etiquetada como candidatos à delinqüência e, como já apresentado aqui, que a criminalidade é responsabilidade de toda a sociedade por conta de seus sistemas repressores seletivos e mantenedores da exclusão, as propostas da criminologia crítica em relação a políticas criminais consistem em modificar e/ou abolir o sistema penal. Portanto, apresenta-se um impasse entre este discurso e os movimentos de defesa dos direitos das mulheres. Enquanto ambos lutam contra os estereótipos e a opressão de sistemas historicamente solidificados, bem como defendem a descriminalização de crimes como o aborto, os criminólogos críticos almejam a descriminalização do direito penal em um sentido mais amplo, enquanto alguns militantes do movimento feminista defendem a criminalização de certas condutas contra a mulher.

A principal crítica feminista contra a criminologia crítica consiste no fato de que esta, ao relacionar as instituições de controle social, não destacou o patriarcado como um mantenedor da desigualdade de gênero (ANDRADE, 1997, CAMPOS, 1998). E na busca por englobar aspectos anteriormente ignorados, a criminologia feminista emergiu sustentando que "a gênese da opressão das mu- 
lheres não pode reduzir-se à sociedade capitalista, pois, se esta oprime a mulher, sua opressão é anterior e distinta, produto da estrutura patriarcal da sociedade" (ANDRADE, 1997, p. 93). Assim, este discurso - que como a criminologia crítica também se caracteriza como movimento social - postula a não estigmatização tanto do criminoso (a) nato (a), com tendências perigosas, quanto da vítima em sua honestidade. Isso porque, da mesma forma que apenas alguns grupos são criminalizados, apenas algumas mulheres que correspondem à figura da mulher honesta são consideradas vítimas. A seletividade ocorre para os dois lados e o discurso criminológico feminista propõe-se a desconstruir ambos.

No discurso da criminologia feminista, a descriminalização dos crimes considerados tipicamente femininos é apresentada, porém a criminalização de comportamentos que colocam a mulher como vítima, como no caso de crimes sexuais e de violência, não são defendidos. Isto se deve pela compreensão de que a relegitimação do sistema penal por meio do endurecimento das leis não protege a mulher, mas aumenta a seletividade sobre a figura do agressor e da agredida, colocando a mulher à mercê da violência institucional do sistema penal que promove o constrangimento por meio da moralidade subjacente a ele (ANDRADE, 1997, CAMPOS, 1998). A proposta deste discurso, segundo Andrade (1997), consiste em alternativas à criminalização destes conflitos que utilizam a prisão como solução, de forma a atender a mulher de uma maneira mais completa do que o mero sequestro legalizado do homem; bem como transportar o embate para a arena do direito constitucional, buscando o respeito à condição da mulher enquanto sujeito. Desta forma, a figura feminina que emerge neste discurso é a da mulher emancipada, livre de amarras jurídicas, que não se submete ao poder do patriarcado, tampouco do direito penal. Isso porque os conflitos criminalizados em questão encontram-se no espaço social e a sua judicialização não significa sua extinção, senão sua expansão para o âmbito jurídico (ANDRADE, 1997). Assim, o discurso criminológico feminista não consiste em uma oposição aos movimentos feministas, considerando que estes próprios não apresentam unanimidade em relação à judicialização de conflitos em decorrência das diversas epistemes que influenciam seus discursos. Se, historicamente, homens e mulheres foram etiquetados por criminologias e sistemas punitivos seletivos que refletiram aspectos de ordem social, política e econômica, as novas criminologias apontam exatamente para um caminho oposto, em que a supressão dos sistemas que exercem o controle tanto social quanto penal acarreta a igualdade de classe e gênero prevista pela constituição brasileira.

\section{CONSIDERAÇÕes FINAIS}

Um mito do senso comum é o de que o direito modifica a sociedade a partir da judicialização de conflitos, como as famílias que são reguladas pelas leis e os sujeitos que são sentenciados por seus crimes. Em fato, o direito e suas normatizações colaboram na manutenção dos aspectos socioeconômicos e políticos de uma dada sociedade. As teorias da criminologia crítica explicitam esta função do direito, no caso, penal. E se esta área do direito assume uma função de mantenedora do controle social, esta não ocorre apenas com base nas legislações e no 
sistema punitivo mas, principalmente, pelos etiquetamentos que proporcionam uma criminalização muito mais complexa do que o mero sequestro institucionalizado. Especificamente no caso da mulher, é possível afirmar que seus estereótipos emergem de discursos sociais, biológicos, psicológicos, e que influenciam as codificações jurídicas de forma a permitir o controle social.

Assim, figuras femininas foram circunscritas ao longo da história por diversos saberes e práticas. É sabido que, por muitos séculos, em comum mantiveram a docilidade, a fragilidade, a dependência, a maternidade e a vocação para a família, sendo inaceitável o comportamento divergente destes. No caso das mulheres autoras de delitos, estas ainda ocupam um espaço de oposição à figura feminina aceita socialmente. Ou, para utilizar-se de um enunciado jurídico apresentado até os dias atuais na codificação brasileira, a mulher criminosa está em oposição à figura da mulher honesta.

E se a oposição deve ser controlada pelo Estado e pelos discursos que possibilitam sua manutenção, então as criminologias até o início do século XX cumpriram sua função. A figura da prostituta, da degenerada moral que além da promiscuidade não resistiria a outros vícios e crimes, esta é condenada. Na busca por identificações físicas das criminosas natas para melhor proteger a sociedade delas, a figura da mulher masculinizada, viril,tão agressiva quanto o homem, também é condenada. A atávica, tão semelhante ao selvagem, que não apresentaria amor materno e seria capaz de matar o próprio filho, também é considerada perigosa. Mas essas figuras da mulher criminosa que são enunciadas pelo discurso criminológico positivista não o são por oferecerem um perigo às outras pessoas, mas por oferecerem risco à sociedade em sua moralidade e costumes. Desta forma, a neutralização destes sujeitos se fez, também historicamente, necessária.

Essas figuras femininas foram criminalizadas legal e socialmente assim como o homem, mantendo geralmente em comum a baixa escolaridade, o subemprego a que são submetidos, a marginalização social e a violência estrutural que os circunda. São figuras construídas e reconhecidas não por serem mulheres, mas por pertencerem a determinados grupos sociais e exercerem determinadas funções. Isso porque, quando comparada ao homem, a mulher junto ao direito penal e às criminologias é relacionada, em muitos casos, à vitimização pela compreensão do período positivista de que a mulher é um ser que mereceria cuidados e proteção por ser inferior e incapaz. Assim, a figura de uma mulher que, apesar de criminosa, é vítima, é uma constante até os dias atuais. O mito de que a mulher não comete delitos não é relacionado a questões biológicas que a diferem do homem, mas a sua repressão diferenciada no tempo e espaço, por códigos que se preocupam em neutralizar aquela que colocaria em risco a instituição da família para além da segurança pública. E é em prol também da família que os códigos, sob influência do discurso criminológico positivista, estipularam papéis fixos e dicotômicos: a mulher honesta nunca viraria prostituta e a prostituta nunca poderia ser vítima de crime sexual. Especialmente a figura da prostituta não mereceria proteção do Estado, segundo este discurso, por ser uma criminosa nata, enquanto a mulher honesta, sim, deveria ser a única figura feminina protegida juridicamente. 
Em meio às figuras da criminosa nata masculinizada, da atávica, da prostituta e da vítima, emerge junto ao discurso criminológico feminista a figura da mulher emancipada. Aquela que não apela a um sistema penal seletivo a fim de resolver conflitos, mas que busca uma cidadania não abstrata, uma cidadania que possa usufruir inteiramente, junto a um direito constitucional que seja aplicado de maneira efetivamente igualitária. Uma igualdade de classe e gênero que o direito penal em sua parcialidade não é capaz de atingir. Uma igualdade, para além do aspecto jurídico, de base social, política e econômica, a fim de que as figuras femininas apresentadas pelas criminologias dos séculos passados não mais legitimem exclusões e marginalizações.

\section{REFERÊNCIAS}

ANDRADE, V. R. P. de. A ilusão de segurança jurídica: do controle da violência à violência do controle penal. Porto Alegre: Livraria do advogado, 1997. 336 p.

BECCARIA, C. Dos delitos e das penas. [1. ed. Itália: s.n., 1764]. São Paulo: Martins Fontes, 1998. 139 p. Coleção clássicos.

BRASIL. Código penal brasileiro: decreto-lei n².848, de 07 de dezembro de 1940.

CAMPOS, C. H. O discurso feminista criminalizante no Brasil: limites e possibilidades. 1998. 141 p. Dissertação (Mestrado em Direito)-Universidade Federal de Santa Catarina, Florianópolis, 1998.

CASTRO, L. A. de. Criminologia da libertação. Rio de Janeiro: Revan, 2005. $284 \mathrm{p}$.

FOUCAULT, M. Vigiar e punir: nascimento da prisão. 29. ed. Petrópolis: Vozes, 2004. $262 \mathrm{p}$.

LOMBROSO, C. O homem delinqüente. [1ª ed. Itália: s.n., 1876]. Porto Alegre: Ricardo Lenz, 2001. 555 p.

PIEPER, E. O. W. A execução penal em Santa Catarina e o tratamento penal feminino. 1992. 183 p. Dissertação (Mestrado em Direito)-Universidade Federal de Santa Catarina, Florianópolis, 1992.

ROSA, A. M. da. Direito infracional: garantismo, psicanálise e movimento antiterror. Florianópolis: Habitatus, 2005. 240 p.

SILVA, I. M. I. da. Direito ou punição? Representação da sexualidade feminina no direito penal. 1983. 248 p. Dissertação (Mestrado em Direito)-Universidade Federal de Santa Catarina, Florianópolis, 1983.

SOARES, O. Criminologia. Rio de Janeiro: Freitas Bastos, 1986. 342 p. 
VENERA, R. A. S. Cortina de ferro: quando o estereótipo é a lei e a transgressão feminina (processos crime de mulheres, em Itajaí - décadas de 1960 a 1999). 2003. 158 p. Dissertação (Mestrado em História)-Universidade Federal de Santa Catarina, Florianópolis, 2003.

ZAFFARONI, E. R. Las “clases peligrosas": el fracaso de um discurso policial prepositivista. Revista Seqüência, Florianópolis, n. 51, p. 141-168, dez. 2005.

Recebido em: abril de 2008 Aceito em: março de 2009 